\title{
The problem of targeted sympathy in justice for sex workers
}

Professor Chrysanthi Leon, Associate Professor of Sociology \& Criminal Justice and founding member of the Center for the Study and Prevention of Gender-based Violence at the University of Delaware, and Professor Corey Shdaimah, Daniel hursz Dist Unuished Professor of Social Justice at the programs (PDPs). These programs ostensibly offer a prose sym prog num the punitive measures which vilify and endanger the lives of sex workers. By introducing the important concept of targeted sympathy, Leon and Shdaimah highlight the vital deficiencies of PDPs, which often fail the very people they seek to protect. Their research attempts to fill a gap in existing literature, which has tended to uncritically (or overly critically) perpetuate reductive stereotypes about sex work. effective forms of meaningful justice.

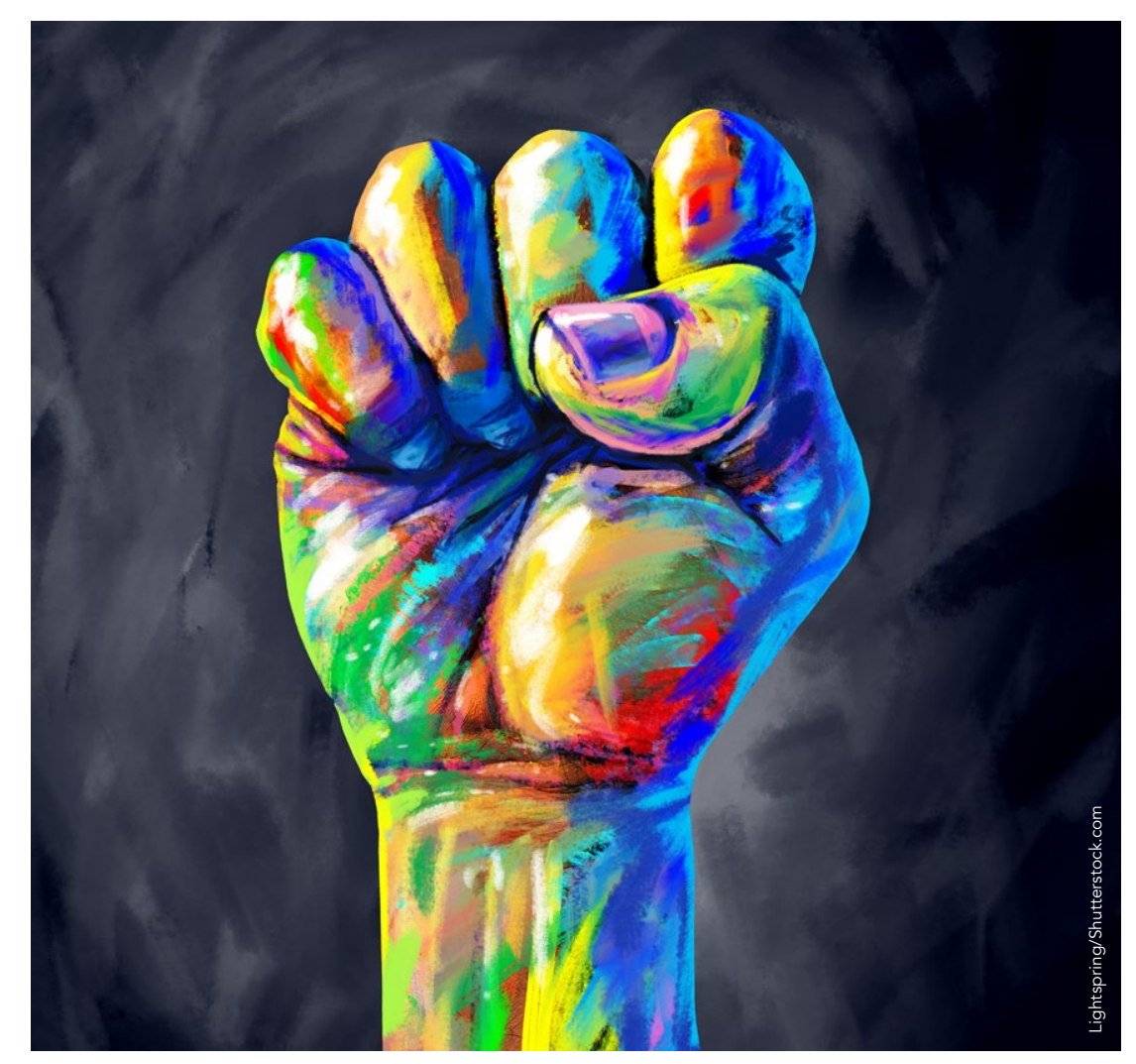

The question of sex work in a legal context often tacitly revolves Put very simply, the question might sex workers victims, criminals, or individuals exercising their agency? This is a debate that both feminists and the criminal justice system have long grappled with, often coming to contradictory and highly insensitive conclusions. Prostitution diversion programs (PDPs) mark progress from traditional justice systems. So-called 'whore courts' ostensibly take a more sympathetic and quasi-therapeutic

Chrysanthi Leon, JD, PhD, and Professor Corey Shdaimah, LLB, LLM, PhD, are concerned that PDPs continue to stigmatise people and provide resource to only a few, particularly by utilising targeted sympathy.

To explore these new forms of problemsolving justice, Leon and Shdaimah conducted research in the field. This was published in their paper Targeted ustice actors' perceptions of prostitution diversion programs. The paper reveals shortcomings of PDPs and highlights the failure of targeted sympathy to solve the problems currently faced by those engaged in street-based sex work.

\section{THE SHORTCOMINGS OF PDPS} Leon and Shdaimah are particularly concerned with the treatment of sex work in recent academic literature. They believe it to be either completely uncritical or
overly critical, such that it overlooks

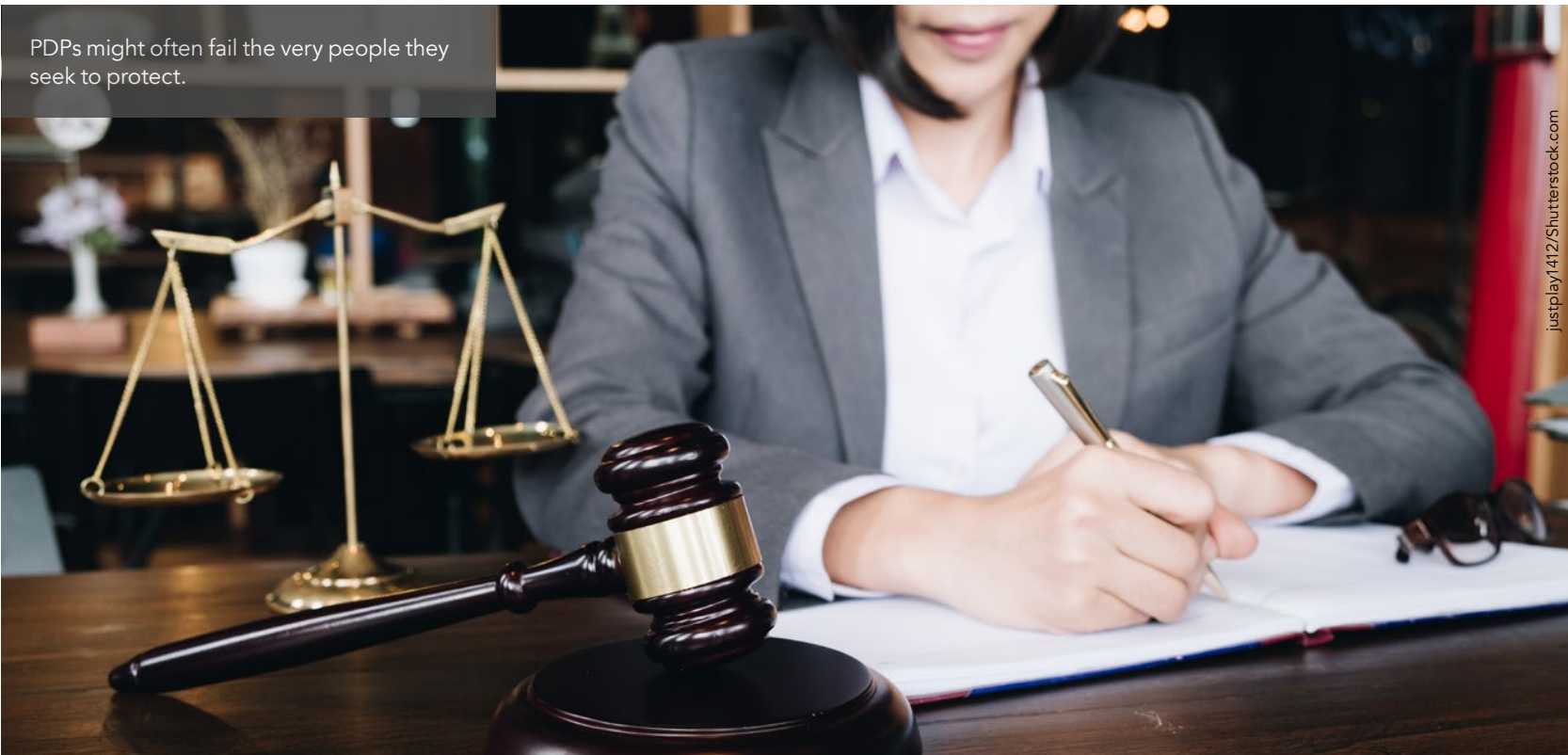

the human context of this contentious subject. Both treatments tend to be sex workers. To reme ty this, thes rile to aims to be critical while remaining grounded, examining nuanced aspects of the legal treatment of sex workers that have thus far been overlooked.

The paper begins by explaining PDPs. These are a form of problem-solving justice that aims not to punish sex work but rather to view them as victims of exploitation. In doing this, courts can

\section{PDPS LEAD TO}

TARGETED SYMPATHY

In much of the world, there exists a

pervasive and entrenched assumption

that sex workers are 'contemptible, emerges out of an unfair focus upon general policing of - women's behaviour US sex work has been criminalised. The corollary of this criminalisation has been that street-based sex workers are forced into dangerous situations, often in underresourced neighbourhoods, and often improve outcomes for sex workers,
giving them a way to giving them a way to leave sex work and
build a better future. Of course, such a view is predicated

Target

sympathy means sympathy is aimed solely at women who fit a certain set of preconditions and assumptions. upon assumptions about what constitutes reflect upon who exactly has actly has the power to

While this is a step forward when compared with the outright prosecution of sex workers, it is only a partial solution. Leon and Shdaimah's view is that PDPs operate according to a contradictory logic. On the one hand, sex workers are viewed as victims who require rehabilitation. On the other, they're expected to take responsibility and be held accountable. This leads to what Leon and Shdaimah refer to as PDP workers opting to 'exploit the pat workers may be further marginalised if they are tra be minorities. Criminalisation, in other words has done little to protect sex workers, and has further jeopardised the position of or overlooked.

PDPs represent a move towards an approach that is both more However, contradictions remain in the attitudes of PDP members, law enforcement, and the general public. For example, they may say that sex coercon, while also choosing to and prosecute. If they were tru arest people who might already be vulnerable compassionate and more effective. of coercion, sex workers would lack the that is typically a required element of criminal offending.

While participating in PDPs, women are asked to analyse their relationships, their behaviour, and their thoughts. This is part of the overall increased surveillance of sex workers, further implying that they the more moral humans. This leads to a narrow set of acceptable problems, or mental illness, which only some women can feasibly be helped through PDPs. The limited and remedies causes the application of and Shdaimah.

\section{MEASURING THE EFFECTIVENESS} OF PDPS

To delve further into targeted sympathy portant gap in the extant research around sex work, Leon and Shdaimah combine data from two quallative studies. One looked at two Philadered PDS in Baltimore and a needs as, while the other examined a needs assessment in Peterson County (a pseudonym is used in this study to protect the confidentiality of participants). They used semi- 


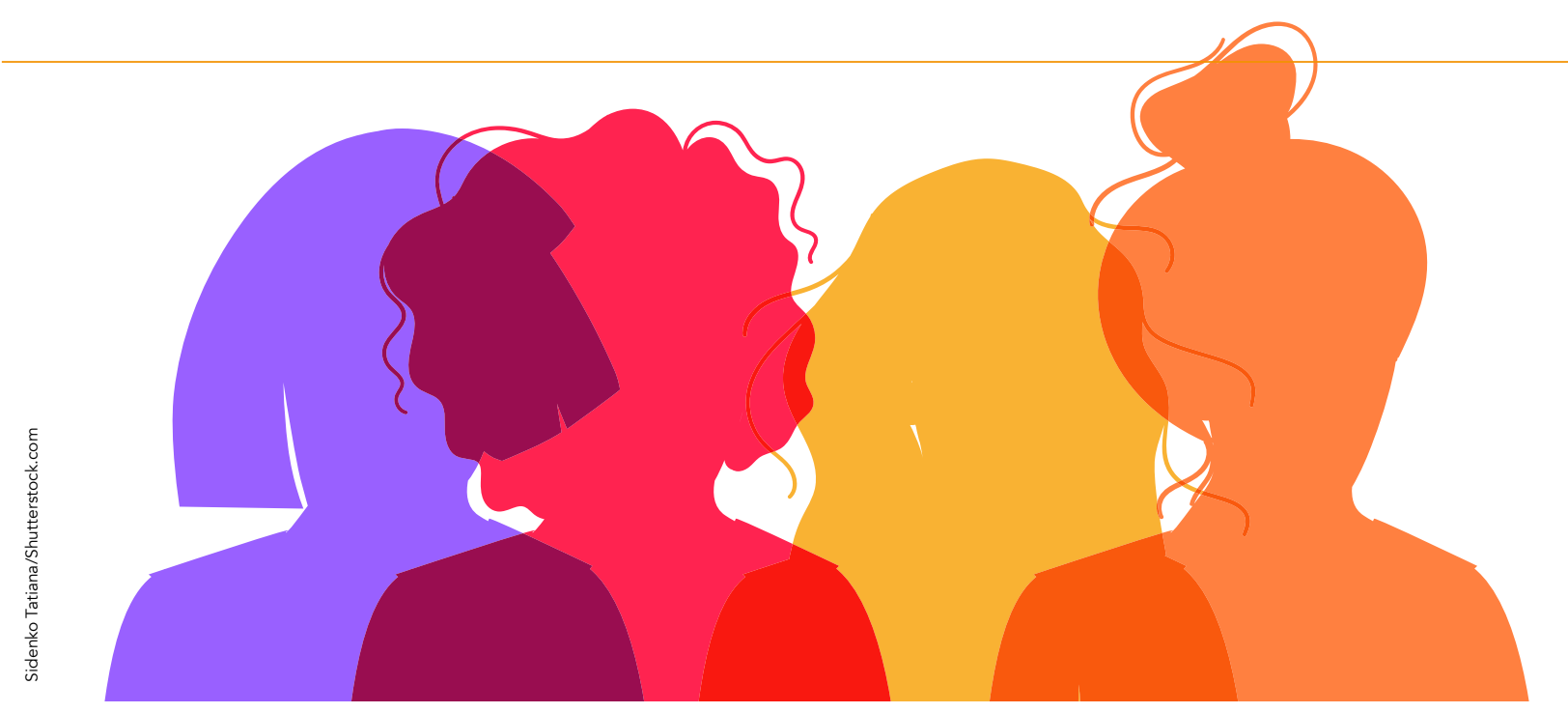

and observations to explore the experiences and expectations of PDP group members.

ostracising those vulnerable women who $\begin{array}{ll}\text { ostracising those vulnerable women who } & \text { Many PDP workers are aware of its } \\ \text { do not conform to the parameters of } & \text { shortcomings. However, they continu }\end{array}$ $\begin{array}{ll}\text { do not conform to the parameters of } & \text { shortcomings. However, they continue } \\ \text { acceptability. These sex workers -deemed } & \text { with it because they view it as the "least } \\ \text { in some way fave } & \text { bad" lternative. Others, though, do not }\end{array}$ stand to gain the most bre these who bad alternative. Others, though, do not right way fonward This cen but tensions earchers could capture responden perspectives in their own words. iterative consensus coding in which they identified key terms and phrases. These included concepts such as 'responsibility', 'trauma', and the of 'who does this?!'

Leon and Shdaimah recognise the limitations of their research. Most significantly, it doesn't review the impact of race, class, and gender on the effectiveness of PDPs. This is because the researchers did not consistently ask participants consistently raity, and it wasn't themselves. This is also a smillipants that combines data from different studes with similar research aims. Nonethe it offers important insights into the effectiveness and desirability of PDPs.

\section{THE FAILURE OF}

\section{TARGETED SYMPATHY}

It is important to remember that PDP professionals interviewed in these studies were there because they had a keen interest in helping sex workers, they have a certain sympathy for them. However, the research suggests that theirs is targeted sympathy, meaning it is aimed at wom who fit a certain set of preconditions and assumptions, reinforcing poten exhibited a 'who does this?!' attitude towards sex work. They viewed it as unsavoury, perhaps even immoral, behaviour. They expressed the view that no one would wake up in the morning and choose to do this kind of work. They believe women are forced into sex work, with no other option.

When women did not fit into this set of assumptions, they were often unable to (n) contradictory beliefs within the minds of workers themselves.

The driving motivation of PDP workers is that they feel compelled 'do something'. They have a deep desire to intervene in order to prevent the cycle of sex work, arrest, incarceration, release, repeat. While this is an improvement on the unsympathetic nature of purely punitive responses, it can be paternalistic and unhelpful. PDPs may
well be the least bad option, but they are a $\begin{array}{ll}\text { ittle more than justice system coercion. } & \begin{array}{l}\text { option, but they are a } \\ \text { long way from being } \\ \text { good enough. Too } \\ \text { often, sexworkers are }\end{array}\end{array}$ $\begin{array}{ll}\text { ittle more than justice system coercion. } & \begin{array}{l}\text { option, but they are a } \\ \text { long way from being } \\ \text { good enough. Too } \\ \text { often, sexworkers are }\end{array}\end{array}$ enjoy the full benefits of PDPs. This form of problem-solving justice, therefore, coercion. Sex workers are expected to exhibit a narrow set of acceptable problems, to take responsibility for their circumstances, and conform to externally enforced moral norm.

\section{THE 'LEAST BAD' OPTION?}

PDP professionals work in quasitherapeutic roles, meaning that they offer a higher level of care towards sex workers than the traditional justice system can provide. However, they also rely on hyperresponsibilisation, in that sex workers are expected to overcome systemic hurdles, without the necessary resources to do so. have long perpetuates the stereotypes failed by the very system which is tasked with protecting their interests.

Leon and Shdaimah's research concludes by recommending that the criminal legal system grapples with the risk of targeted sympathy. This self-awareness is the first step towards overcoming the continued stigmatisation of sex workers. There remains a power imbalance between PDP workers and those who are charged with prostitution. More research must be done to examine the contradictory logics of problem-solving justice so that we can move towards a solution that centers sex workers, focusing on demolishing structures of inequality rather than implementing justice

\section{Behind the Research P \\ Professor \\ Chrysanthi Leon}

E: santhi@udeledu T: +13024630406 T: +1 3028310426 W: www.ssw.umaryland.edu/academics/faculty/corey-shdaimah W: sites.udel.edu/leon-research W: $\mathbf{i}$-poemproject.wixsite.com/udel

Research Objectives

Professor Chrysanthi Leon and Professor Corey Shdaimah research prostitution diversion programs (PDPs), introducing the concep of targeted sympathy, in order to find more effective forms of justice.

\section{Detail}

Bio

Chrysanthi S Leon, JD, PhD, is Deputy Dean of the Honors College, Associate Professor of Sociology and Criminal Justice, and founding member of the Center for the Study and Prevention of Gender-based She foc e the University or Delaware. teaches in a local women's prison. Corey Shdaimah, LLB, LLM, PhD is Daniel Thursz Distinguished Professor of Social Justice at the University of Maryland School of Social Work, and Academic Coordinator of the MSW/ JD Dual Degree Program. Her research
examines policy implementation with a focus on childcare, dependency court, and street-based sex work.

\section{Funding}

US Office on Women's Health, Office of Public Health and Science, Departme of Health and Human Services, Grant/ Award Number: WH-CCE-10-001

\section{References}

Leon, C, Shdaimah, C, (2021) Targeted sympathy in 'whore court. Criminal justice actors' perceptions of prostitution diversion programs. Law and Policy, 43(3), 126-148.

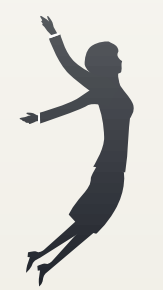

\section{Personal Response}

\section{How much of an improvement are PDPs over} traditional justice systems?

III As feminist scholars we call for critical scholarship that accounts for context. The devil is in the details: including how they compare to existing alternatives. PDPs may provide welcome options, but they are individualised responses to broader problems. They are risky and stigmatising for sex workers. We worry that PDPs deflect
our attention from systemic changes our attention from systemic changes. 